\title{
Carex poculisquama Kük. (Cyperaceae) and its distribution in Korea
}

\author{
Jeong-Ki Hong, Sun-Yu Kim¹, Jin-Seok Kim, Gi-Heum Nam and Jung-Hyun Kim* \\ Plant Resources Division, National Institute of Biological Resources, Incheon 22689, Korea \\ ${ }^{1}$ Exhibition and Education Division, Nakdonggang National Institute of Biological Resources, Sangju 37242, Korea \\ (Received 3 March 2016; Revised 10 March 2016; Accepted 16 March 2016)
}

\section{장군대사초(사초과)와 그 분포 \\ 홍정기 · 김선유 ${ }^{1}$ - 김진석 · 남기흠 · 김중현* \\ 국립생물자원관 식물자원과, 1 국립낙동강생물자원관 전시교육실}

\begin{abstract}
Carex poculisquama Kük., recorded only in the literature in Korea, was confirmed to be distributed in limestone zones in the country. Carex poculisquama is most similar to species in the section Occlusae, such as C. ligulata Nees, but it differs in its rhombic-elliptic perigynium and by the presence of short hairs on the veins of its utricles. We provide here a description, illustrations, and photographs of $C$. poculisquama and a key to the species.
\end{abstract}

Kewwords: Carex poculisquama, sect. Occlusae, Cyperaceae

적 요: 국내에서 문헌에만 기록되어 있던 장군대사초(Carex poculisquama Kük.)가 우리나라 석회암지대에 분포하는 것으로 확인되었다. 장군대사초는 과포가 마름모상 타원형이고, 맥 위에만 단모가 있다는 형태적인 특징으로 같은 절내 근연종인 갈사초(Carex ligulata Nees)와 구분된다. 본 연구에서 장군대사초의 실체를 확 인하고, 기재, 도해, 화상자료를 통하여 근연종과의 차이점을 검색표로 작성하였다.

주요어: 장군대사초, 갈사초절, 사초과

사초속(Carex L.)은 사초과(Cyperaceae)에서 가장 큰 속 으로 전 세계적으로 2,000 여 종이 온대와 한대지역에 널 리 분포하고, 열대의 산악지대와 아프리카지역에서 드물 게 나타난다(Koyama, 1961; Ohwi, 1965; Reznic et al, 1990). 국내에는 157 분류군, 일본에는 202 분류군, 중국에는 527 분류군이 분포하는 것으로 알려져 있다(Ohwi, 1965; Oh, 2007; Dai et al., 2010).

한반도산 갈사초절(sect. Occlusae)에는 장군대사초와 갈 사초(C. ligulata Nees) 두 분류군이 분포하고 있으나 학자에 따라 사초절(sect. Carex)의 민숲이삭사초(C. drymophila var. abbreviata (Kük.) Ohwi), 곱슬사초(C. glabrescens (Kük.) Ohwi), 벌사초(C. lasiocarpa var. occultans (Franch.) Hultén), 융단사초(C. miyabei Franch.), 화산곱슬사초(C. raddei
Kük.) 등과 함께 Hirtae절로 처리하기도 한다(Ohwi, 1936, 1937; Koyama, 1961, 1962; Im, 2000; Katsuyama, 2005; Oh, 2006; Im, 2008; Dai et al., 2010; Hoshino et al., 2011).

장군대사초(C. poculisquama Kük.)는 국내의 경상남도 장군태산에 분포하는 것으로 문헌기록으로만 알려져 있 었으며(Lee, 1996), 그 외에는 분포 - 기재된 바 없던 분류군 이다. 일본은 Honshu와 Kyushu의 석회암지대 초지에 분포 (Katsuyama, 2005; Hoshino et al., 2011)하고, 중국은 Anhui, S Jiangu, Zhejiang의 호수나 배수로 근처 습한 곳에서 분포 하는 고유종으로 인식되어 왔다(Dai et al., 2010).

본 연구는 국내에서 문헌에만 기록되었던 장군대사초 에 대한 실체를 확인하고 채집된 확증표본을 바탕으로 외 부형태학적 기재와 근연종과의 차이점을 검색표로 작성

\footnotetext{
*Author for correspondence: kimjh4065@hotmail.com
} 
하는 것을 목적으로 수행되었다.

\section{분류군의 기재}

Carex poculisquama Kük., Repert. Spec. Nov. Regni Veg. 27: 111. 1929.

국명: 장군대사초(Jang-Gun-Dae-Sa-Cho)

다년생으로 지하경이 짧으며, 바닥을 긴다. 줄기는 모여 나며, 길이는 30-70 cm로서 가늘고 삼각형이다. 표면은 약간 껄껄하고 엽초는 없거나 짧다. 상부의 잎은 화서보 다 길지만 하부의 잎은 화서보다 짧거나 같다. 잎은 선형 이고 길이는 (4)8-16(20) cm, 너비는 2-4 mm로 담록색이 다. 엽연과 향축면은 껄껄하고 다소 긴 엽초가 있다. 맥은 자주색이고, 향축면의 주맥에 골이 있다. 화서는 총상화 서로서 소수는 3-5개가 달리며, 포엽은 화서의 길이와 비 슷하거나 길고, 다소 짧은 엽초가 있다. 웅소수는 선형이 고 길이는 1-2 cm로 자소수 보다 짧으며, 화경이 있다. 자 소수는 선상 원주형이고, 하단부의 소수와 멀리 떨어져

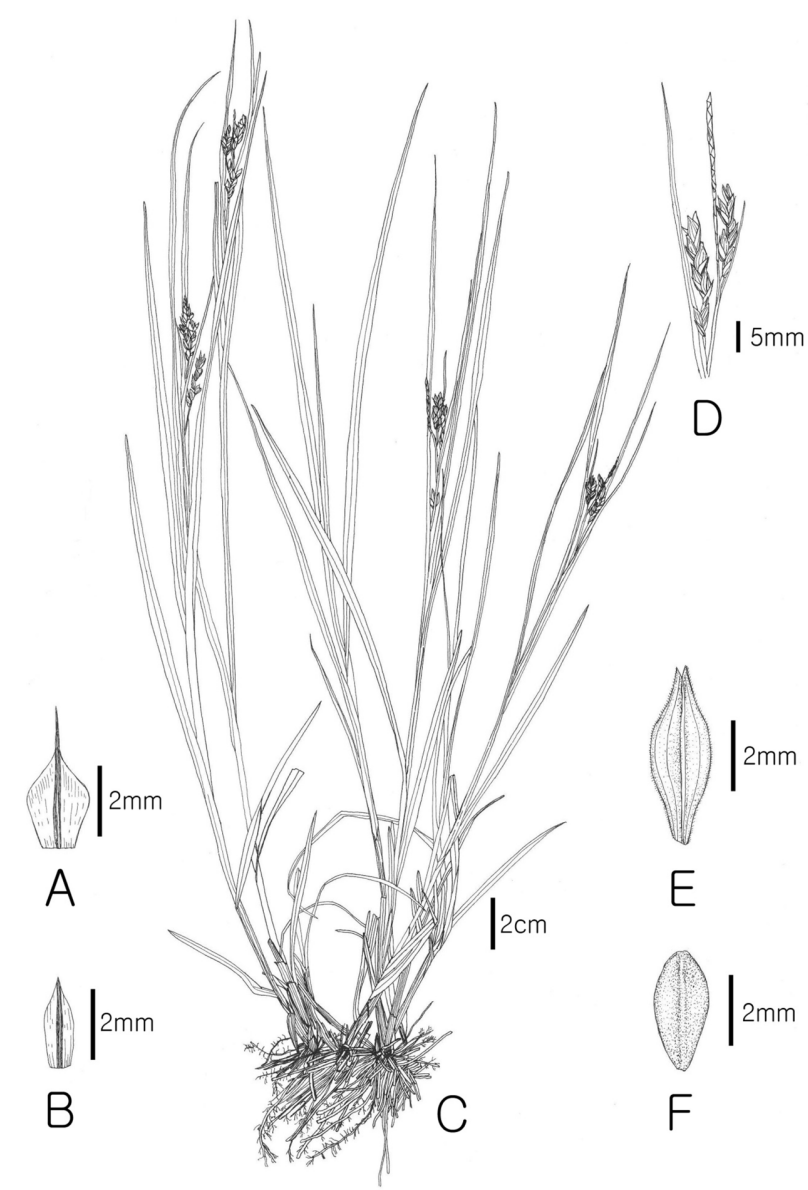

Fig. 1. Illustrations of Carex poculisquama Kük. A. Staminate scale; B. Pistillate scale; C. Habit; D. Inflorescence; E. Perigynium; F. Achene.
있다. 길이는 1-4 cm이고 10 개나 그 이상의 꽃이 달리며, 가는 화경이 있다. 주두는 3 개로 갈라지며, 자주색이고 기 부가 약간 굵다. 웅인편은 담록색이며, 위쪽을 향한 까락 이 있고 예두이다. 자인편은 담록색이고 넓은 난형이며, 둔두이고 길이는 약 $4 \mathrm{~mm}$ 이다. 적갈색의 반점이 있고 1 개 의 맥이 있으며, 정단에 까락이 있다. 과포는 회록색으로 자인편 보다 길고 마름모상 타원형이고 삼릉형이며, 길이 는 4-5 mm이다. 많은 맥이 있고 껄껄하며, 맥 위에 단모가 있고 부리는 2 치가 된다. 수과는 충실하며, 3 각, 도란형이 고 길이는 2.5-3 mm이다(Figs. 1, 2).

분포: 한국(강원도 영월군 한반도면 후탄리, 충청북도 제천시 수산면 수산리 사무산, 다불리 사무산, 괴곡리 사 무산, 경상남도 장군태산), 중국(Anhui, S Jiangu, Zhejiang), 일본(Honshu, Kyushu)

관찰표본: Korea, Gangwon-do, Yeongwol-gun, Hanbandomyeon, Hutan-ri, 13 Jun. 2015, J.H. Kim and Y.H. Cho J.H Kim152124, 152125 (KB). Korea, Chungcheongbuk-do,

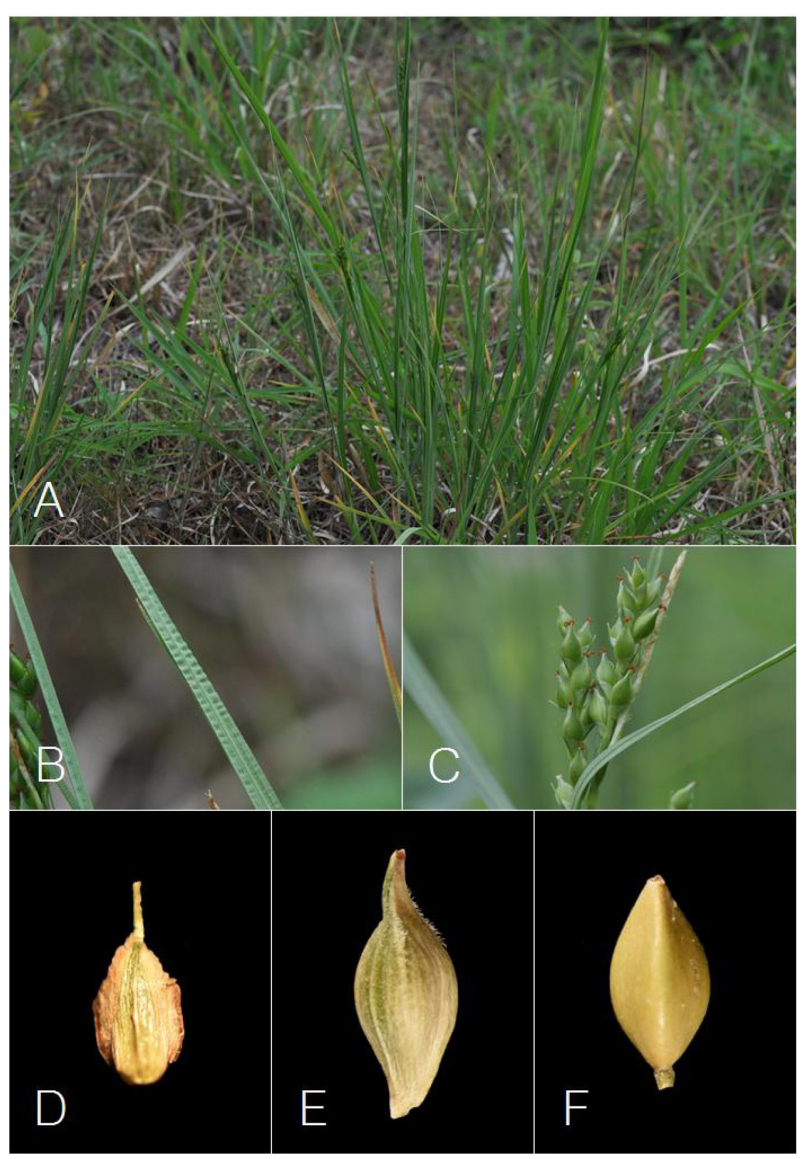

Fig. 2. Photographs of Carex poculisquama Kük. A. Habit; B. Crisped leaf; C. Inflorescence; D. Staminate scale; E. Perigynium; F. Achene. 
Jecheon-si, Susan-myeon, Susan-ri, Samusan (Mt.), 02 Jun. 2014, Kim et al. kis130463, 130451, 130452, 130453, 130454, 130455, 130456, 130457, 130458, 130459, 130460, 130461, 130462 (KB), 26 May 2015, Jung et al. L15072, Samu150331, 150342, 150343, 150344, 150345, 29 Jun. 2015, Jung et al. Samu150602, 150635, 150636, 27 Jul. 2015, J.H. Kim and S.Y. Kim Samu150863, 150867, 24 Aug. 2015, Jung et al. Samu151098 (KB). Dabul-ri, Samusan (Mt.), 27 May 2015. Jung et al. Samu150529, 150530, 150531, 150532 (KB). Goegok-ri, Samusan (Mt.), 28 Jul. 2015, J.H. Kim and S.Y. Kim Samu151004 (KB).

\section{근연분류군과의 검색표}

1. 줄기 끝의 웅소수는 1 개이고, 측소수는 대부분 자소수 이다. 과포 끝의 부리는 짧으며, 2 치가 얕게 갈라진다

2. 자소수의 과포가 성기게 달린다. 과포는 마름모상 타원형이고, 맥 위에만 단모가 있다

장군대사초 . poculisquama

2. 자소수의 과포가 빽빽하게 달린다. 과포는 난형 또 는 도란형이고, 전체적으로 강모가 밀집한다

갈사초 C. ligulata

1. 줄기 끝의 웅소수는 2-3개이다. 과포 끝의 부리는 길고, 2 치가 깊게 갈라진다

3. 엽초에 털이 없다

4. 잎의 폭은 1.5-3 mm이고, 과포의 부리가 짧다 ….... 벌사초 C. lasiocarpa var. occultans

4. 잎의 폭은 3-6 mm이고, 과포의 부리가 길다

5. 자소수는 서로 떨어져 달리고, 과포의 부리는 급하게 좁아진다 …............ 융단사초 C. miyabei

5. 자소수는 서로 가까이 달리고, 과포의 부리는 점차 좁아진다 …………..... 곱슬사초 C. raddei

\section{3. 엽초에 털이 있다}

6. 과포와 부리에 털이 없다 ... 화산곱슬사초 C. raddei

6. 과포와 부리에 털이 있다

숲이삭사초 C. drymophila

\section{고 찰}

장군대사초는 자소수의 과포가 성기게 달리며, 과포는 마름모상 타원형, 맥 위에만 단모가 있다는 형태적 특징 에 의해 절내 근연종인 갈사초와 구분된다. 일본에서는 장군대사초가 일본과 중국에 분포하는 것으로 알려져 있 으며, 중국에서는 고유종으로 인식되고 있다(Katsuyama, 2005; Dai et al., 2010).

특이생육지 식물다양성 조사 - 연구 중에 국내에서는 처 음으로 강원도 영월과 충청북도 제천에서 장군대사초의 자생지를 확인하였다(Fig. 3). 두 자생지의 생육환경은 매 우 건조한 양지바른 산지의 무덤가 주변이었다. 사무산
자생지는 잣나무(Pinus koraiensis Siebold \& Zucc.), 아까시 나무(Robinia pseudoacacia L.)가 상층림을 형성하고, 관목 층에 조팝나무(Spiraea prunifolia var. simpliciflora (Nakai) Nakai), 갈기조팝나무(Spiraea trichocarpa Nakai), 화살나무 (Euonymus alatus (Thunb.) Siebold), 붉나무(Rhus javanica L.) 등, 초본층에 으아리(Clematis terniflora var. mandshurica (Rupr.) Ohwi), 좀꿩의다리(Thalictrum minus var. hypoleucum (Siebold \& Zucc.) Miq.), 고삼(Sophora flavescens Aiton), 띠 (Imperata cylindrica var. koenigii (Retz.) Benth. ex Pilg.), 산 둥굴레(Polygonatum thunbergii C. Morren \& Decne.)가 우점 하며, 그 외 까치수염(Lysimachia barystachys Bunge), 댕댕 이덩굴(Cocculus trilobus (Thunb.) DC.), 딱지꽃(Potentilla chinensis Ser.), 산딸기(Rubus crataegifolius Bunge), 멍석딸 기(Rubus parvifolius L.), 호비수리(Lespedeza davurica (Laxm.) Schindl.), 아마풀(Diarthron linifolium Turcz.), 새머 루(Vitis flexuosa Thunb.), 개아마(Linum stelleroides Planch.), 백선(Dictamnus dasycarpus Turcz.), 반디지치(Lithospermum zollingeri A. DC.), 갈퀴꼭두선이(Rubia cordifolia var. pratensis Maxim.), 더위지기(Artemisia sacrorum var.

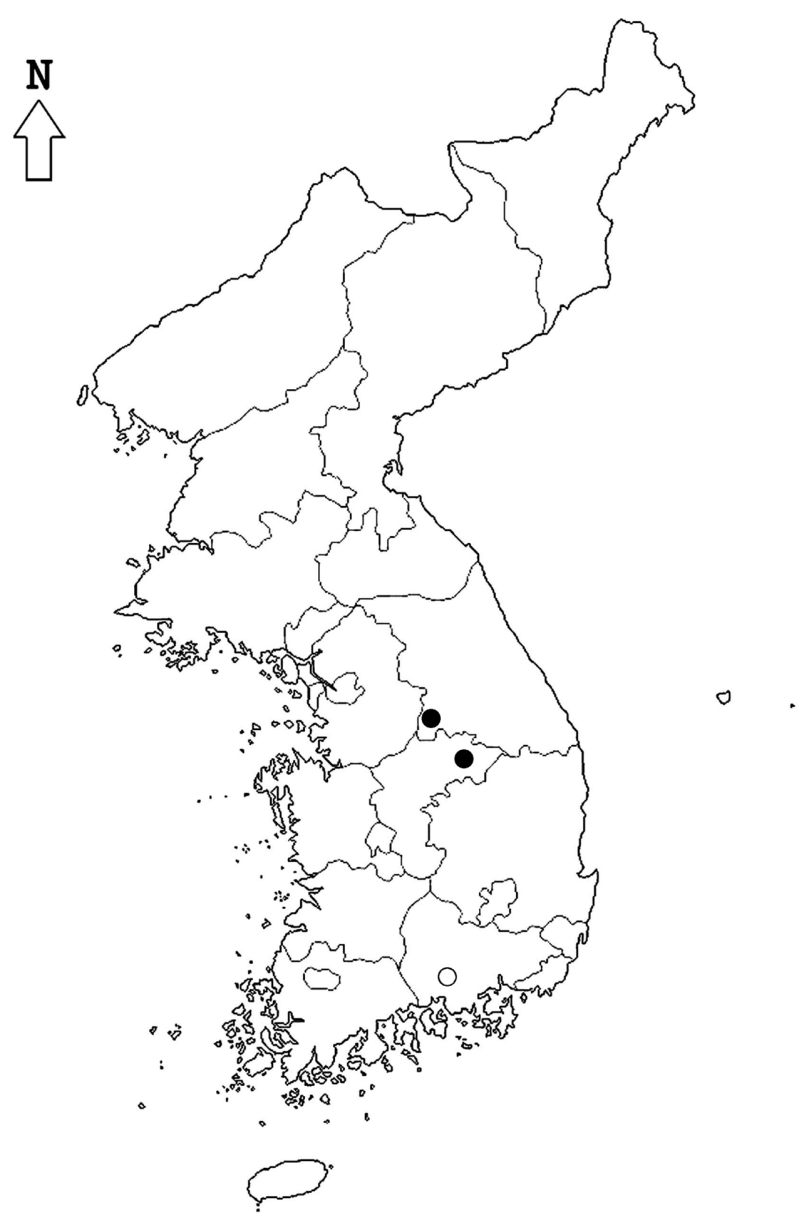

Fig. 3. Distribution map of Carex poculisquama Kük. in Korea. field survey; $\bigcirc$. literature search. 
iwayomogi (Kitam.) M. S. Park \& G. Y. Chung), 엉겅퀴(Cirsium japonicum Fisch ex DC.), 고들빼기(Crepidiastrum sonchifolium (Bunge) J. H. Pak \& Kawano), 뻐꾹채(Rhaponticum uniflorum (L.) DC.), 쇠채(Scorzonera albicaulis Bunge), 억새(Miscanthus sinensis Andersson), 털중나리(Lilium amabile Palib.), 범부채 (Belamcanda chinensis (L.) DC.), 각시붓곷(Iris rossii Baker), 마(Dioscorea oppositifolia L.) 등이 혼생하며 생육하였다. 장 군대사초는 광량이 많은 산지 무덤가에서 관찰되어 건조 한 생육환경에서 자라는 양지식물임을 알 수 있었다. 사무 산의 산지 능선부에서도 개체군을 형성하나, 울폐된 식생 하부에서는 확인되지 않는 점으로 보아 내음성은 약한 것 으로 판단된다. 두 지역은 석회암층의 노두가 확인되는 곳 으로 호석회식물들이 다수 관찰되는 점도 특이하다. 한편 국내에서 경상남도 장군태산에 분포(Lee, 1996)한다는 문 헌기록을 바탕으로 개화기와 결실기에 각각 현장조사를 실시하였으나 그 실체를 확인할 수 없었다.

본 종은 일본에서 적색목록 취약종(Vulnerable)으로 평가 하고 있으며, 전 세계적으로 매우 희귀한 분류군으로 석회 암지대에만 잔존하는 것으로 알려져 있다(Katsuyama, 2005; Hoshino et al., 2011). 한반도 내에서 확증표본에 근거 한 분포역도 석회암지대에서만 발견되고 있는 것으로 보 아 일본의 생육환경과 유사한 것으로 보이며, 매우 건조 한 환경에 특이적으로 격리 분포하는 것으로 생각된다. 그러나 중국의 자생지는 Anhui, S Jiangu, Zhejiang 지역의 호수나 배수로 근처 습한 곳에서 분포하고 고유종으로 인 식하고 있어 추후 확인이 필요한 부분이다(Dai et al., 2010). 또한 갈사초절에 속한 분류군의 기준이 학자마다 차이가 있어 갈사초절에 속하는 식물군과 사초절에 속하 는 식물군에 대하여 외부형태학적, 분자분류학적 연구가 필요한 것으로 판단된다.

앞으로 지속적인 생물상조사가 수행되면 국내의 다른 석 회암지대에서 추가적인 분포지가 확인될 것으로 예상되며, 이에 기초한 자생지 정보와 확증표본은 한반도 적색목록 등재에 따른 평가자료 등의 정보로 활용될 수 있을 것이다.

\section{사 사}

본 논문은 정부(환경부)의 재원으로 국립생물자원관의 지원을 받아 수행되었습니다(NIBR201401104; NIBR201 501104).

\section{Literature Cited}

Dai, L. K., S. Y. Liang, S. R. Zhang and Y. C. Tang. 2010. Carex L. In Flora of China, Vol. 23. Z. Y. Wu, P. H. Raven and D. Y. Hong (eds.), Science Press and Missouri Botanical Garden Press, Beijing and St. Louis. Pp. 285-461.

Hoshino, T., T. Masaki and M. Nishimoto. 2011. Illustrated Sedges of Japan. Heibonsha Ltd., Tokyo. Pp. 414-417.

Im, H. T., K. S. Kim and B. U. Oh. 2008. Carex miyabei Franchet. (Cyperaceae) and its distribution in Korea. Korean Journal of Plant Taxonomy 38: 539-545. (in Korean)

Im, R. J. 2000. Flora Coreana. The Science and Technology Publishing House. Pyengyang. (in Korean)

Katsuyama, T. 2005. Carex of Japan. Bun-ichi Sogo Shyuppan, Tokyo.

Koyama, T. 1961. Classification of the family Cyperaceae (1). Journal of the Faculty of Science, University of Tokyo, Section III. Botany 8: 37-148.

Koyama, T. 1962. Classification of the family Cyperaceae (2). Journal of the Faculty of Science, University of Tokyo, Section III. Botany 8: 149-278.

Lee, W. T. 1996. Lineamenta Florae Koreae. Academy Press, Seoul. (in Korean)

Oh, Y. C. 2006. Illustrated Encyclopedia of fauna \& flora of Korea. Vol. 41. Ministry of Education and Human Resouces Development, Seoul. (in Korean)

Ohwi, J. 1936. Cyperaceae Japonicae I. A synopsis of the Caricoidae of Japan, including the Kuriles, Saghalin, Korea, and Formosa. Memoirs of the College of Science; Kyoto Imperial University. Series B. Biology 11: 229-530.

Ohwi, J. 1937. Symbolae ad floram Asiae orientalis plantae novae Japonicae. Acta Phytotaxonomica et Geobotanica. 6: 145150.

Ohwi, J. 1965. Flora of Japan. Smithonian Institution. Washington, DC.

Reznicek, A. A. 1990. Evolution in sedges (Carex, Cyperaceae). Canadian Journal of Botany 68: 1409-1432. 